\title{
UNIVERSITYOF
}

FORWARD

THINKING

WESTMINSTER用

WestminsterResearch

http://www.westminster.ac.uk/westminsterresearch

From green park to theme park? Evolving legacy visions for

London's Olympic Park

Smith, A.

This is the accepted author manuscript of an article subsequently published in revised form in Architectural Research Quarterly / Volume 18 / Issue 04 / December 2014, pp 315-323.

(C) Cambridge University Press, 2015

The online edition of the journal article at Cambridge Journals Online is available at:

https://dx.doi.org/10.1017/S1359135515000056

The WestminsterResearch online digital archive at the University of Westminster aims to make the research output of the University available to a wider audience. Copyright and Moral Rights remain with the authors and/or copyright owners.

Whilst further distribution of specific materials from within this archive is forbidden, you may freely distribute the URL of WestminsterResearch: ((http://westminsterresearch.wmin.ac.uk/)).

In case of abuse or copyright appearing without permission e-mail repository@westminster.ac.uk 


\section{From green park to theme park? Evolving legacy visions for London's Olympic Park}

\section{Introduction}

The Queen Elizabeth Olympic Park (QEOP) opened to the public in 2013/4. In the preceding ten years the future of this two hundred and fifty hectare site in East London was subjected to intense debate, planning and envisioning. This paper analyses the evolving vision for the Park during this period. The analysis contributes to the literature on this significant case, but it also helps us to appreciate the challenges associated with event-led urban projects and the design and management of public parks in the $21^{\text {st }}$ century. The paper is based on the author's attendance at over thirty seminars, conferences and public events 2004-2014 at which officials and relevant professionals presented their work and ideas about the Park ${ }^{\mathrm{i}}$. These presentations were analysed alongside the enormous amount of policies, plans and strategies (and accompanying media coverage) published to reveal the sort of place that was envisioned by the professionals hired to shape it.

It is impossible to do justice to the complexities of the project in the space available here. So the paper concentrates on one key shift in emphasis - the move away from the original vision of large parklands and a blueprint for sustainable living towards a more bombastic, iconic landscape that is organised and promoted as a destination. This explains the transition from green park to theme park posited in the title of this paper. With reference to this shift, it is important to emphasise that the QEOP has never been envisaged as a traditional theme park. However, some characteristics that have emerged in recent years suggest there may be relevant parallels with theme park urbanism, a concept closely associated with Michael Sorkin following the publication in 1992 of his (edited) book entitled 'Variations on a Theme 
Park'. In the introduction to this text, Sorkin describes how urban designers now produce urban spaces characterised by ageographia, control and 'simulations without end'. For Sorkin, 'this is the meaning of the theme park' ${ }^{\text {ii }}$.

The broad visions of those involved in planning the future of the Olympic Park are the focus here, so the paper constitutes an analysis of what, in Lefebvrian terms, should be considered 'representations of space': the conceptualised spaces of planners ${ }^{\text {iii }}$. The Park has only recently been fully open to the public. Consequently it is too early to examine how the space is being lived, reconfigured and reimagined by the people who use it. This is perhaps the most important dimension of space. However, the way spaces are lived depends partly on how they were conceived and this is the focus in this paper. One of the first accounts of experiencing the QEOP once it re-opened reported 'the sense on the ground of a place being modelled from a plan you can't quite fathom'iv. This commentary highlights the interrelation of design intentions, conceptual models and lived experiences.

\section{Context}

It is important to provide some context and an outline of the work undertaken to plan the long-term future of London's Olympic Park: a process known as legacy planning. This will help explain why some changes disused here occurred, but it will also assist those unfamiliar with the London 2012 project to navigate the rest of the paper. Shifting visions for the Park 2004-2014 were inevitable, not only because of the length of time under consideration, but also because of the project's complexity and the underlying political and economic turbulence. Taking these factors into account one might have expected far greater drift. 
The complexity of the project relates not only to the multiple interests involved, but also to the multiple stages: preparing a bid / delivering the Games / planning for the long-term. The Park was designed for the 2012 Olympic and Paralympic Games, but it was also made to be remade. In other words, the masterplanners had to configure a specialised events site, but also provide a framework for future development. At key points the long-term vision was formalised in masterplans and planning applications: 2003/2004 when candidature documentation and outline plans for the Olympic Park were produced; 2005-2007 when Masterplans and related planning applications were written; and 2008-2012 when the Legacy Masterplan / Legacy Communities Scheme and Supplementary Planning Guidance for the post-Games (re)development of the Park were prepared/approved. Alongside planning documents, key stakeholders published consultation documents, policy statements and public information that also communicated the legacy vision ${ }^{\mathrm{v}}$.

The institutional complexity involved is perhaps best illustrated by the fact that the three institutions that produced plans during the period 2004-2012 no longer exist - the London Development Agency (LDA), Olympic Delivery Authority (ODA) and Olympic Park Legacy Company (OPLC). The LDA co-ordinated land assembly and legacy planning in the early stages of the project (2004-8); with legacy planning assumed by a new Legacy Company established in 2009 (the OPLC ${ }^{\text {vi }}$ ). In 2012, responsibility for the Olympic Park and its fringes passed to a new agency accountable to the Mayor of London: the London Legacy Development Corporation (LLDC). These institutional changes were linked to wider political changes: changes of administration at the city and national levels in 2008 and 2010 respectively. Other contextual changes were also significant; perhaps most importantly the global financial crisis. These factors caused a drift away from some of the original 
aspirations. The discussion below assesses whether visions of a large, sustainable park were retained, before analysing the emergence of new priorities: tourism and revenue generation.

\section{Green park}

In the initial, hypothetical, period of planning for London's Olympic Park (2003-4), the purposes of the envisioning were clear; the project needed to impress the International Olympic Committee and bring a sceptical press and parliament onside. The difficulties delivering a new national stadium and the aborted attempt to host the 2007 World Athletics Championships had seemingly proven the UK's inability to deliver mega-projects. In this climate, one way to justify public expenditure was to promise a park. Parks are rare assets in urban planning; although they can be expensive to maintain, there is universal consensus that they are good thing. In the 'Vision for the Olympic and Paralympic Games', published to justify a London Games centred in the Lower Lea Valley, the bid team promised that:

'at its heart would be the new 500 acre Olympic Park containing the major sporting facilities and set in 1500 acres stretching from Hackney Marshes down to the Thames. It would be one of the largest new parks seen in Europe for 200 years'vii.

Although the legacy vision to deliver a new park has never been reneged upon, there has been a subtle downscaling of the original ambitions. Parklands south of the Olympic Park connecting it to the Thames have not been realised yet due to several factors, not least the financial crisis. The 2004 London Plan, the Spatial Development Strategy into which the Olympic bid was integrated, had proposed a linear park in the Lea Valley. Indeed, the wording in the vision cited above is taken from the 2004 London Plan and the Olympic 
Games were initially justified as way to accelerate the linear park project. However, once the Olympic bid was won, there was a conscious refocusing on a more tightly defined area in and around the Olympic Park at the expense of other sites governed by the London Thames Gateway Development Corporation (West Ham, Canning Town and Barking Riverside). More focus was welcomed by many involved in urban regeneration who felt the Thames Gateway plans for East London were too ambitious, particularly in an austerity era. This all highlights how the Olympic Park became a project in its own right rather than merely one part of a wider East London regeneration. The new parklands are currently confined to a limited stretch of the Lower Lea Valley.

Another aspect of the (c.2004) London 2012 vision cited above, the idea that the Olympic Park 'would be one of the largest new parks seen in Europe for 200 years', is also worth scrutinising. During the period 2004-2012 various iterations of this statement were disseminated to help justify the Olympic project, with the general trend being to downscale the original promise. By 2007 official documents were promising 'one of the largest new urban parks in Europe for 150 years'viii. In 2012 the Government were merely promising the 'biggest urban park for a century' ${ }^{\text {'ix }}$. To assess whether the parklands dimension has actually diminished is a challenging task. Measuring the size of parklands or open space is technically difficult as definitions are vague. According to the 2007 planning approval, the authorities are obliged to provide 102 hectares of open space. This still applies, although there are some concerns that plans for housing and other developments might erode this provision. For example, the Olympic Legacy Supplementary Planning Guidance highlights the potential impacts of new housing on the 'overall quantity and quality of new public space and metropolitan open land required by the 2007 Olympic planning approval'x . 
Even though promises to deliver the 102 ha of open space are currently being honoured, it is also important to take into account subjective perceptions. Much of the open space in the Olympic Park is characterised by hard surfaces - ideal for staging events but not necessarily the grassy park people were expecting or were promised. In 2008 new designs were released that showed how 'the Olympic Park will become a Hyde Park for East London'xi. This type of rhetoric seemed to communicate that the Olympic Park would be typical of London's Royal Parks. This was later reaffirmed by naming the new park the Queen Elizabeth Olympic Park. However, the QEOP is unlike a traditional park ${ }^{\mathrm{xii}}$. The linear shape and multiple levels of this waterside site also make the green / open space seem limited. Current plans are certainly less 'green' than designs proposed in 2008 which included a cricket pitch, orchards, allotments, an events lawn, a city farm and a One Planet ecology pavilion.

The idea that the Olympic Park was ultimately about new parklands was challenged by a creeping urbanism in visions for the Olympic Park. Evidence of this shift appeared soon after the bid was won. The British Property Federation released a report stating that 'it is extremely welcome that the Masterplan for the main Olympic site involves raising the density significantly to give it a proper urban character' xiii. And in 2007 the ODA confirmed that 'the vision for Games legacy is ... to create a vibrant new part of London that exhibits the best of

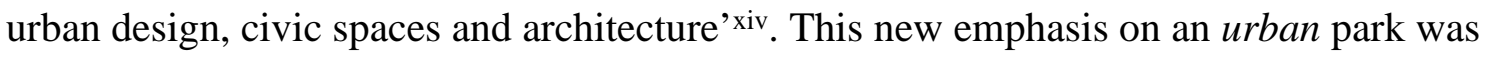
perhaps most obvious in the ODA's new rhetoric that they were building 'a piece of city' rather than building Europe's biggest park for 200/150/100 years. Representatives from surrounding Boroughs recommended that the Park should be developed as an urban centre rather than as a recreational area serving existing centres. This was linked to the idea that the Park should not be a liminal place but an integrated one that felt like a part of East London, or London in general. 
Envisioning the Park as an urban setting was furthered in the OPLC-led vision of generously proportioned family housing. Previously, the vision was for multi-storey apartments surrounding a generously proportioned park - in a manner similar to New York's Central Park. The OPLC's idea was to provide housing that was both more family oriented and more like London's traditional homes: low rise housing; and crescents organised like London's great estates. Accordingly, the 2012 Legacy Communities Scheme included proposals for terraced housing east of the media centres. The obvious problem with this approach is that low rise family oriented units require more space. The LLDC are committed to minimum open space stipulations but the Park will be getting smaller over time as housing developments commence. This is not widely appreciated so the new developments may be viewed negatively by park users. This problem has occurred before in UK event projects; for example the National Garden Festival regeneration projects of the 1980s. These Garden Festivals were not meant to create parks - but this was not always understood by the public, causing controversy when festival sites were redeveloped for housing ${ }^{\mathrm{xv}}$.

In the bid documents submitted to the IOC, London's bid team promised that 'the development of the Olympic Park will transform 200 hectares of degraded land into a magnificent new legacy park' ${ }^{\text {xi }}$. Significantly, the bid committee were not just promising a new park; they were promising to replace degraded land with a new park. This type of rhetoric continued to appear throughout the next decade, and exemplifies a typical 'motivational frame' ${ }^{x v i i}$ for urban development. Urban regeneration projects are often framed by the denigration of the site in order to justify large scale change. Hence during the planning and visioning of the Olympic Park, the site was dismissed as a wasteland or a void that needed to be filled. Many of the officials tasked with making the Olympic Park used similar 
rhetoric and imagery to justify their project. In many presentations, officials showed a before and after A-Z map with the site represented as a blank space on one side of the slide and as an Olympic Park on the other. Such practice is the not only the epitome of framing, but the perfect illustration of the power of representations of space. The circa $2005 \mathrm{~A}-\mathrm{Z}$ map was presented as the reality that needed to be fixed, rather than merely a cartographic depiction. Other parts of the framing were equally spurious; the dismissal of the site by officials as a dumping ground for refrigerators when in fact this was merely one small part.

The framing of the project as a way of replacing toxic wastelands is particularly relevant here because it inherently dismissed the recreational land and open space that was available on the site before it became an Olympic Park. The ODA planning application in 2007 revealed that there were 92.8ha of open space prior to the Olympic project, a figure only just below the 102ha promised in the new Olympic Park. This inconvenient truth was recognised by MPs in 2003 - prior to government commitment to the project - when the site was described as "not just derelict land needing restoration, but rather a precious and tranquil green lung'xviii. Ultimately, ten years of legacy planning delivered formalised, institutionalised recreational space in the north of the park, instead of the loose, vague recreational space that existed before.....

\section{Green park 2: a sustainable park?}

The idea of a green park not only means parklands, it means a park that is environmentally sustainable. This notion was also prominent in early visions for the Olympic Park: from 2007 one of the key aims of the London 2012 project was to make the Olympic Park 'a blueprint for sustainable living' ${ }^{x i x}$. The idea of building prototypes for environmentally friendly or 
socially progressive urbanism is a common feature of mega-event projects, particularly World Expos. During the period 2007-2011 many good examples of sustainable design and sustainable management were implemented in the Park ${ }^{\mathrm{xx}}$. However, over time, sustainability became less prominent in legacy visions ${ }^{\mathrm{xxi}}$. This was perhaps most obviously illustrated in the Government's document 'Beyond 2012', in which the notion of the Olympic Park being a blueprint for sustainable living, was replaced with the idea of the Park as 'a blueprint for modern living' xxii.

Making the Park a model of sustainability has been hampered by a series of missed opportunities. The large wind turbine that was planned for the north of the park was jettisoned; primarily because of cost issues. Other potentially iconic symbols of sustainability - e.g. the energy centres - are now overshadowed by the more contrived symbols such as The Orbit viewing tower. There was an ideal opportunity to showcase sustainable design principles during the Olympic Games, but a long planned exhibition was accessible only to those with 'backstage' accreditation and attracted a mere 2,000 visitors ${ }^{x x i i i}$. Hosting green technology businesses in the Park was also discussed. The failure of this to be realised or formally incorporated into plans helped fuel criticism that legacy planners were too concerned about job creation, at the expense of consideration about the types of employment that might be most beneficial.

Parks and environmental sustainability share some important characteristics: both have very positive meanings and both are conveniently vague concepts. This made them extremely useful in helping to justify staging the Olympic Games in the early envisioning of the project. Officials have attempted to honour ambitious promises of new, sustainable parklands. However, in later visions these ambitions were de-emphasised and obscured by aspirations 
that were hard to square with mundane recreational / sustainability objectives: the rise of tourism considerations and 'destination making'.

\section{Destination making and theme park urbanism}

From the outset, the Olympic Park was imagined as a place that would provide jobs and housing, plus much needed educational and transport improvements. These ambitions were largely retained 2004-2014, with recent evidence suggesting many may be realised. This is a considerable achievement, particularly given the complexity of the project. However, during the course of the project, other objectives appeared too. One of the emerging considerations was the need for the Park to be developed as a destination able to attract domestic and international visitors. The idea of the Olympic Park as a destination gathered pace after the election of Boris Johnson as Mayor of London (2008) and the establishment of the OPLC (2009). Rather than merely providing local amenities, the Park would be a 'global visitor attraction' that would attract 9.3 million visitors a year from $2016^{\mathrm{xxiv}}$. This was entirely consistent with a shift away from an East London agenda, to 'a greater emphasis on the London-wide and global orientation' ${ }^{\mathrm{xxv}}$. It also fits Silk's observation that 'competitive city

reimaging for the external tourist market has been central in the build-up to the Games' ${ }^{\text {xxvi }}$.

The new destination emphasis was materialised in the plans for and construction of the Arcelor Mittal Orbit [hereafter The Orbit] - a sculpture introduced in 2010 that contradicted many of the design principles of the Park. In the initial years of Olympic Park planning (2004-7), the 2008 Beijing Games were at the top of people's minds and London officials were keen to avoid competing with the Chinese capital's grand structures. London's response was to adopt the opposite approach: a lighter touch, sustainable Olympic precinct displaying 
'straightforward common sense and legacy planning'xxvii. This was exemplified by the designs for the Velodrome and Olympic Stadium. The Orbit marked the official end of this sensible approach and its bombastic design sat awkwardly with the post-2008 period of austerity; making it seem outdated even before the structure was finished.

There are multiple explanations for the decision to build The Orbit, but ultimately it was part of a plan instigated by the new Mayor to drive footfall in the Park and to give the site a stronger image as a destination. Its appearance has been the subject of much comment and much criticism, with one high profile verdict denigrating both its appearance and its inherent unsustainability: '[it] looks like the result of a competition to see who could piss the most steel into the air'xxviii. In presentations given by OPLC officials, crass comparisons were made with the Eiffel Tower: a structure also built as part as part of a mega-event (the 1889 Exposition Universelle). These parallels were made to legitimise and monumentalise the controversial sculpture. However, structures develop iconicity over time; and there is a chequered record of those deliberately built to serve as destination / event icons ${ }^{\mathrm{xxix}}$. Inevitably, Anish Kapoor, one of the artists responsible for The Orbit's design, has tried to distance himself from the idea that this was an attempt to impose an icon: 'we didn't want an icon, we wanted a moving narrative' ${ }^{\mathrm{xxx}}$. Its justification as a piece of artwork is undermined by paid for entry, which not only limits interaction with the work ${ }^{\mathrm{xxxi}}$, it has meant the installation of 'a harsh fence and lumpy support buildings which do nothing to help the park feel like a park' xxxii.

[INSERT FIGURE 1 HERE] 
The Orbit was not merely built as a sculpture, but as a viewing platform and visitor attraction xxxiii; something that further cements the Park's new envisaged role as a tourist destination. Theme park urbanism, subtly evident elsewhere, is manifested here in a more obvious manner - particularly as The Orbit looks like a 'scrunched-up rollercoaster'xxxiv or a helterskelter [see Figure 1]. Interestingly, in recent visions for the QEOP, some of the Olympic venues have also been recast as 'must-see' attractions. Publicity materials produced by the LLDC are replete with tourism tropes; the indoor sport venues (Velodrome, Aquatics Centre, Copper Box), are promoted alongside The Orbit and Stadium as the 'big five' attractions. This is just one part of the LLDC's impressive promotional work; their branding of the QEOP is very strong. Even their public facing website domain name 'noordinarypark.co.uk' highlights the way they are trying to communicate that the Park is more than a set of local amenities; and therefore worth visiting. What is being created is a 'brandscape' ${ }^{x x x v}$; a heavily marketed and highly controlled environment where consumers are immersed and seduced. The revised design of the Park, particularly the introduction of The Orbit, assists brandscaping by making it more easily reducible to simple imagery. The product being sold is 'big sport'; not informal recreation or outdoor activity, but big events plus sport you have to pay for at the VeloPark ('feel the thrill on two wheels') or Aquatics Centre ('swim in the pool of champions' $)^{\mathrm{xxxvi}}$.

A new tourist oriented landscape is being created in more subtle ways too. Tourism academics have noted the way that successful destinations tend to be highly 'imageable', not only allowing them to be conveniently branded, but more easily 'consumed' in person. According to Edensor ${ }^{\mathrm{xxxvii}}$, touristscapes tend to frame environments from above or from a distance, so tourists can take possession of them. This tallies with the OPLC's legacy masterplan that 'seems to be about creating vistas and views across the park' xxxviii. Edensor 
also feels that serial touristscapes are spaces saturated with imagery which is normally consumed before one enters the space. Hence visitation becomes a process of collecting signs, rather than a spontaneous experience ${ }^{\mathrm{xxxix}}$. This certainly resonates with the QEOP, where tourists are invited to rediscover the edifices they consumed whilst watching the Olympic Games on television.

Touristscapes are usually the result of what planners / designers think tourists want, rather than something that tourists actually want. The Olympic Park fits this trend nicely; it is a landscape designed with the archetypal tourist in mind, even though tourists are increasingly hard to profile and despite the lack of evidence that tourists want anything different from other users of urban space. Indeed, one of the great urban tourism successes of recent years is New York's High Line: which is the opposite of an iconic landscape ${ }^{\mathrm{xl}}$. To emulate this success the LLDC recruited one of the designers responsible for the High Line to develop one 'Corner' of the Olympic Park. This hasn't necessarily alleviated the theme park feel. Moore feels the Park represents a 'Disneyfied' version of New York's High Line ${ }^{x l i}$.

It is not merely the appearance and marketing of attractions, and the landscape design, that marks the Olympic Park as a tourist destination: it is also the organisation and management of space. Sorkin ${ }^{x l i i}$ famously compared the design and management of contemporary cities to theme parks; citing the ageography, surveillance and simulated environment as shared characteristics. These definitely relate to the planned environments of the QEOP; which exhibit Sorkin's dystopia of 'generic urbanism' and 'grafted signification' and which 'allow people to circulate through threatening urban territory'xliii. The QEOP has been designed using the organisational structure of the theme park; the zoning of space, the high security and the disjointed eclecticism of the architecture. Post-Games planning for the Olympic Park 
seems to be a good example of strategic re-territorialisation ${ }^{\text {xliv }}$. Space becomes territory through its organisation, but also through naming and installations. Accordingly, Park space has been organised into themed zones; with new installations - e.g. The Orbit - marking this as a monumental space for sight-seeing. Re-territorialisation as destination is assisted by giving the whole area a new name: E20 / QEOP. The space and the way it has been marketed is so reminiscent of a commercial theme park that posters advertising the reopening of the Park in 2014 had to emphasise that there was FREE ENTRY. As the main entrance / exit is through a new Westfield shopping mall, the ultimate stereotype in theme park design is also present: exit through the gift shop.

The QEOP is not a theme park. However, the idea that it can be understood as a 'variation on a theme park' has merit. Various journalists and critics have also drawn similar parallels. When the ODA completed their work on the Park, Paul Hayward wrote that 'the country finds itself constructing a sporting Disneyland'xlv, whilst Iain Sinclair described the Park as 'a theme park without a theme'xlvi. In a related metaphor, others have described plans for the space as 'la-la land, a fantasy world, the kingdom of the birds'xlvii. The 'other-wordly-ness' of the spaces is perhaps an inevitable function of the huge levels of resources devoted to the project. In some instances mega-event sites have not been planned enough, but others have been subjected to too many competing plans ${ }^{x l v i i i}$. Officials in London, paranoid about reproducing the redundant Olympic landscapes in Athens, have layered plan on plan and devoted huge sums of money to redevelop spaces. Monclus identifies the dangers of this kind of 'investment overdose' in mega-event projects: something he defines as; 'the excessive concentration of resources in a limited space with the physical risk of the formation of enclaves or precincts poorly integrated to the urban structure or at the danger of an excessive 
standardisation, theming or banalisation of the project spaces' ${ }^{\text {xlix }}$. The QEOP is the latest example: too much planning and excessive resources - resulting in a contrived space.

In late 2013 The Mayor of London revealed his latest plans for the Park: Olympicopolis. In doing so he reaffirmed the shift towards destination making outlined above. New museums satellite 'branches' of established brands - are now planned for part of the Park, to provide cultural attractions and an educational dimension that some felt was missing. One of the main influences on this vision seems to be the legacies of previous events in London. The Southbank and South Kensington were both developed in association with major events (the Festival of Britain and the Great Exhibition) and the latest plans attempt to provide an eastern equivalent. According to a former Director at the LLDC, this new direction was the result of pressure from local Boroughs for more 'wow factor' in the Park'. Their belief is that only a spectacular place will allow the Park to drive the re-imaging, revitalisation and redevelopment of East London more widely. The Orbit, Westfield and grandiose sport stadia are seemingly not enough, an even more 'iconic' landscape is required.

Olimpicoplis highlights the way visions, plans and long-term intentions are superseded by unexpected opportunities and emergent strategies. This is how mega-event landscapes from Seville to Sydney have evolved - not by realising long-term plans, but through opportunistic

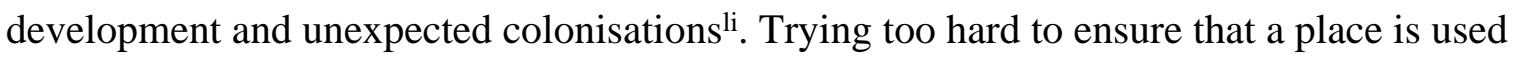
may actually be counter-productive: recent urban design ideas emphasise the importance of space which invites different uses and users rather than imposing a fixed idea of what and who space is forlii. This flexible approach challenges the whole notion of legacy planning - a discourse that dominated the visions for London's Olympic Park 2004-2104. Legacies cannot be imposed on spaces; they emerge. 


\section{Competing visions?}

The analysis above highlights how visions evolved over time, but it should also be noted that there were multiple visions being communicated at once, with some contradictions evident. For example, the new emphasis on creating a spectacular destination co-exists with the notion that the Park should reflect east London / London more widely. These ideas seem hard to reconcile. The OPLC and now the LLDC have been adamant that the site should merge into its periphery, yet the rhetoric of building a new piece of city - and the allocation of a new postcode - suggests it has always been the intention to build something new and distinct, rather than an extension of the existing urban environment. This distinction suits (risk averse) property developers too. The destination emphasis is also incongruent: theme park urbanism is the epitome of segregated space. There are also contradictions in the spatial dimensions of the visions. The Mayor of London wants to avoid high rise housing, yet the low rise urbanism he advocates eats into the land available for cultural attractions and recreational space and normalises his spectacular destination.

The distinct zoning of space is the way that these conflicting visions may be reconciled. Officials involved argue that the QEOP is big and diverse enough to satisfy different visions simultaneously. The North Park has been promoted as a calmer, more locally oriented place with the South Park earmarked as the events / destination zone. Following this logic, rather than dismissing the QEOP as a theme park, it might be better understood as an international destination with an adjoining local park.

\section{Explanations and implications}


An enormous amount of time and resources have been expended over the past ten years to plan the future of London's Olympic Park. The sheer volume of documents, strategies and plans produced has been remarkable. Ambitious objectives were set, and the project has made a significant contribution to the provision of local housing, employment and transport facilities. The main objective here was not to judge the outcomes of these efforts, but to identify ways that legacy plans for the Olympic Park have shifted. Although there is an obvious danger of over-simplification, it seems the notion of sustainable parklands, whilst still present, has been overtaken by a vision for a more bombastic and a more urbanised setting: one 'crammed with spectacular attractions and activities' as the Mayor of London puts it ${ }^{\text {liii. }}$. The shift in emphasis is neatly symbolised by the revised vertical dimension of the Park; with plans for a 130 metre wind turbine replaced by a 115 metre viewing tower. This new approach overshadows the potential iconicity of some of the Park's exemplars of sustainability, such as the energy centres. The impressive design of these structures convinces Hartman ${ }^{\text {liv }}$ that they will act as beacons of sustainable development. But The Orbit and other public sculptures - plus the decision to retain a large stadium on site - means they are increasingly obscured.

It is possible to explain why these changes have occurred via reference to some obvious truths. All mega-projects evolve and this one is no different. Urban mega-projects usually span several electoral cycles; and when political leadership changes so do projects, particularly if they are linked to something as politically significant as the Olympic Games. In the case analysed here, there was also drift because of shifting institutional responsibility for legacy planning ${ }^{\mathrm{lv}}$. With hindsight, there may have been a more consistent and more coherent (albeit less pluralistic) vision had the ODA overseen both initial masterplanning and 
subsequent legacy planning. However, the discussion here also highlights that mega-projects are not merely delivered by one organisation; a large number of institutional stakeholders are involved. In London this meant constant pressure (e.g from Host Boroughs) to envision the Park in a manner that suited diverse interests. As Yaneva and Heaphy ${ }^{\text {lvi }}$ have argued in this journal with reference to the Olympic Stadium, high profile projects may begin as a technical and aesthetic objects, but they inevitably turn into inherently social designs 'the building becomes a multiple object; an assembly of contested issues: community development, sustainability, legacy and cost'lvii. This is even more relevant when one considers the Olympic Park as a whole, rather than merely its principal structures. Protracted and inconsistent legacy planning 2004-14 may be regarded by some as inefficient, but it provides evidence of negotiated representations of space.

Visions for mega-projects are not simply plans to configure space, they are produced at different times, for a variety of reasons and for diverse audiences. The original plans for the Olympic Park were designed to impress the IOC and to bring a sceptical public onside. Sustainable credentials helped to impress the former, and even hardened sceptics found it hard to oppose the construction of a public park on land branded useless and toxic. This was vision as justification (for the event) - one might say visionary justification - something required at the early stages of mega-event projects (particularly given their poor track record). The idea that mega-events are catalysts for regeneration is widely accepted, but in reality regeneration projects are often used tactically by event hosts to help justify their extravagance. Following this logic, mega-events may benefit more from their coupling with regeneration projects than regeneration projects benefit from mega-events. 
Despite acknowledgment of the need for long-term planning, during the mid-stages of the project officials were understandably distracted by the need to deliver a successful event. This emphasises a key problem with event-led projects; even though long-term objectives are used to justify them, the event inevitably becomes the central concern. Legacy plans then have to be retrofitted over a landscape which is already configured. In London, as the postGames period approached, so did the reality of developing and managing a large site. At this stage, plans were made to address the original objectives but also to impress investors - to fund the development of the Park and to pay back the money borrowed to purchase, remediate and redevelop land. In a culture of cost-saving and income generation, sustainability initiatives and social legacy projects tend to be neglected. This highlights a further key problem with mega-event projects; financial pressures caused by spending on the event mean that post-event plans for sustainable development are compromised in the rush to claw back money.

Parks are valuable social amenities, but they are also development assets and so any further reductions in parklands to provide housing are misguided financially, as well as for more altruistic reasons. As the ODA recognised in their original design principles for the Park 'the lush green setting will also help to drive land value and investor interest in development

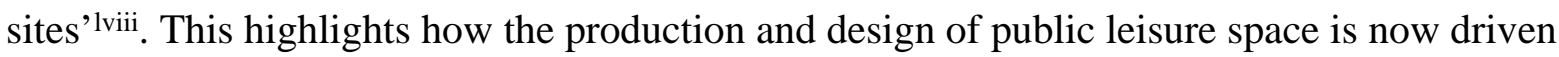
by the need to support economic outcomes ${ }^{\text {lix }}$. Hence new parks are developed in conjunction with hospitality, retail and housing provision, rather than as entities in their own right. The QEOP is a good example of this trend: ultimately, the parklands make the surrounding commercial and property developments viable. The new emphasis on this dimension, and its contrast with earlier visions, is entirely predictable. Mega-event projects are often justified initially by the provision of social assets with 'commercially exploitable phases and 
precincts' introduced later. ${ }^{1 \mathrm{x}}$ As Evans ${ }^{\mathrm{xi}}$ notes; each story of regeneration begins with poetry and ends with real estate.

The LLDC are under pressure to generate regular income, as well as capital returns. There is currently a budget shortfall and according to the Greater London Authority 'the ability of the LLDC to generate income depends heavily on attracting large numbers of visitors to the QEOPlxii. This explains the new emphasis on tourism and the intense brandscaping noted in this paper. In this sense, the QEOP is a good illustration of the difficulties faced by park designers and managers in the $21^{\text {st }}$ century. In London, public funding for parks is being reduced significantly, with parks expected to make up the shortfall via commercial revenues. The new reality of park management is best illustrated in the recent Nesta publication 'Rethinking Parks'lxiii where recommendations are dominated by one theme: how to maximise income generation ${ }^{\text {lxiv }}$. In this context, and in light of difficulties making previous Olympic sites sustainable financially, it is perhaps unsurprising that commercially oriented visions for the Olympic Park have gained prominence.

\section{Notes}

\footnotetext{
${ }^{i}$ These included: public information events organised by the London Development Agency, the Olympic Park Legacy Company, the London Legacy Development Corporation and the Greater London Authority; events put on by think tanks, professional institutions and interest groups, as well as external events staged at various Universities.

ii Michael Sorkin 'Introduction' In Michael Sorkin (Ed) Variations on a Theme Park: The New American City and the End of Public Space (New York: Hill and Wang, 1992, p.xv)

iii Henri Lefebvre The Production of Space (Oxford: Blackwell, 1991)

iv Tim Adams 'Crowds return to the Olympic Park' The Observer (28/07/2013, p.3)

${ }^{\vee}$ For a timeline of the evolution of the project see Andrew Smith 'De-risking East London. Olympic
} 
regeneration planning 2000-2012' European Planning Studies 22(9), 2014, pp. 1919-1939

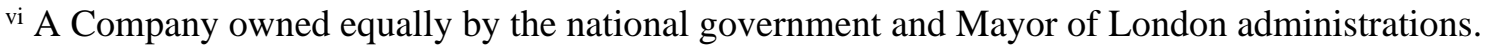

vii London 2012 'London 2012: A Vision for the Olympic Games and Paralympic Games’ (London:

Haymarket Publishing, 2004)

viii Department for Culture, Media and Sport Our Promises for 2012 (London: DCMS, 2007)

ix Department for Culture, Media and Sport ‘Beyond 2012: The London 2012 Legacy Story’ (London:

DCMS, 2012). Available at: https://www.gov.uk/government/publications/beyond-2012-the-london-

2012-legacy-story

× Greater London Authority Olympic Legacy Supplementary Planning Guidance (London: GLA, 2012, p. 61)

${ }^{x i}$ Robert Booth ‘Olympics will leave east London an open space to rival Hyde Park’ The Guardian (17/03/08). Available at http://www.theguardian.com/uk/2008/mar/17/olympics2012.regeneration xii 'it feels like an exhibition of hard standing and balustrades with a park struggling to get out' Rowan Moore (2014) 'Let the Games begin again' The Observer (06/04/13, p. 23)

xiii R Holt The Olympics and the London Property Market. A Paper for the British Property Federation (London: Experian, 2005)

${ }^{\text {xiv }}$ Moore, 'Let the Games begin again'

${ }^{x v}$ Robert Holden 'British garden festivals: The first eight years' Landscape and Urban Planning 18(1), 1989, pp. 17-35

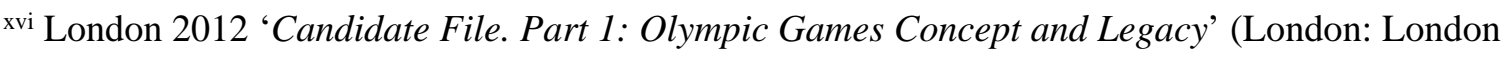
2012, 2004)

xvii Erving Goffman Frame Analysis: An Essay on the Organization of Experience (Cambridge MA, Mass: Harvard University Press, 1974)

xviii House of Commons Olympics. Government Response to “A London Olympic Bid for 2012” HC 268) Report of the Culture, Media and Sport Select Committee Session 2002-2003.

${ }^{x i x}$ DCMS 'Our Promises'

xx Hattie Hartman London 2012 Sustainable Design: Delivering an Olympic Legacy (Oxford: John 
Wiley and Sons, 2012)

xxi John Gold and Margaret Gold 'Bring it under the legacy umbrella: Olympic host cities and the changing fortunes of the sustainability agenda' Sustainability 5(8), 2013, pp.3526-3542

xxii DCMS ‘Beyond 2012’ p.72

xxiii Gold and Gold 'Bring it under the legacy umbrella'

xxiv OPLC Queen Elizabeth Olympic Park (London: OPLC, 2010)

${ }^{x x v}$ Juliet Davis and Andy Thornley 'Urban regeneration for the London 2012 Olympics: Issues of land acquisition and legacy' City, Culture and Society 1(2), 2010, pp.89-98.

xxvi Michael Silk ‘Towards a sociological analysis of London 2012' Sociology 45(5), 2011, pp.733-

748

xxvii Albena Yaneva, and Liam Heaphy 'Urban controversies and the making of the social'

Architectural Research Quarterly 16(1), 2012, pp.29-36

xxviii Moore, 'Let the Games begin again'

xxix These include Thomas Heatherwick's disastrous B of the Bang sculpture installed at Manchester's pseudo Olympic Park, SportCity.

xxx Adams ‘Crowds Return'

xxxi Jen Harvie 'Brand London 2012 and the heart of East London: competing urban agendas at the 2012 Games’ Contemporary Theatre Review 23(4), 2013, pp.486-501

xxxii Moore 'Let the Games begin again' p.24

xxxiii Indeed, it is promoted as a destination in its own right.

${ }^{\text {xxxiv }}$ Marina Hyde 'Dizzying dreams triumph over crass commercialism at the Olympic Park' The

Guardian (29/07/12)

${ }^{x x x v}$ Anna Klingmann Brandscapes: Architecture in the Experience Economy (Cambridge, MA: MIT Press, 2007)

xxxvi In this sense, the Park shares similarities with current proposals in Barcelona to turn their underused Olympic hub on Montjuic into a sports theme park. Ironically, given the London 2012 agenda to promote sport participation and the traditional role of parks, provision for traditional outdoor sports 
has never really been pivotal in the vision for the Olympic Park. Hence, there is a conspicuous lack of football pitches, cricket pitches etc.

xxxvii Tim Edensor 'Mundane mobilities, performances and spaces of tourism' Social \& Cultural Geography 8(2), 2007, pp.199-215

xxxviii Kieran Long 'Fun after the Games’ Evening Standard (05/10/11, p.38)

xxxix This is a theme in classic tourism texts such as Dean MacCannell The Tourist (Berkeley:

University of California Press, 1976) and John Urry The Tourist Gaze (London: Sage, 1990)

${ }^{x l}$ The High Line does provide opportunities to frame the surrounding urban environment, but is not itself designed as an iconic landscape.

xli Moore, 'Let the Games begin again'

xlii Michael Sorkin 'Introduction’ In Michael Sorkin (Ed) Variations on a Theme Park: The New American City and the End of Public Space (New York: Hill and Wang, 1992, pp.xi-x) xliii Sorkin, Ibid

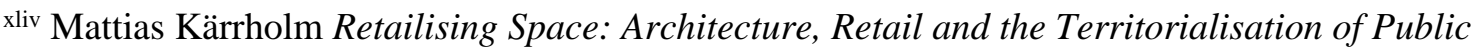
Space (Aldershot: Ashgate, 2012)

xlv Paul Hayward ‘17 Epic Days to Dream’ The Observer (24/07/11, p.1)

${ }^{x l v i}$ Iain Sinclair Ghost Milk. Calling Time on the Grand Project (London: Penguin)

xlvii Rowan Moore 'Let's have an Olympic legacy like this’ Evening Standard (17/02/09)

xlviii Francisco Javier Monclús International Exhibitions and Urbanism: The Zaragoza Expo 2008

Project (Aldershot: Ashgate, 2009)

${ }^{x l i x}$ Francisco Javier Monclús ‘International exhibitions and planning. Hosting large-scale events as place promotion and as catalysts of urban regeneration' In Culture, Urbanism and Planning Francisco Javier Monclus and Manuel Guardia (Eds) (Aldershot: Ashgate., 2006, pp. 215-239).

${ }^{1}$ John Geoghan 'Shifting legacy: why Olympic Park plans are changing' Planning Resource, August 2014. Available at: http://www.planningresource.co.uk/article/1305473/shifting-legacy-why-olympicpark-plans-changing

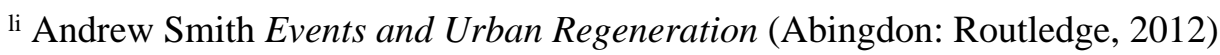


lii Krystallia Kamvasinou 'Vague parks: the politics of late twentieth-century urban landscapes' Architectural Research Quarterly 10(3-4), 2006, pp.255-262

liii Miranda Bryant and Matthew Beard 'Come on down to the 24 hour Olympic Park!' Evening Standard (2/4/14, p.6)

liv Hattie Hartman 'Is sustainability just another “ism”?’ Architectural Design 82(4), 2012, pp.136140.

${ }^{\text {Iv }}$ Lead professionals also move on, with their replacements inevitably introducing changes in emphasis. The pressures, controversies and differences of opinion associated with these types of projects make the departures of senior staff even more likely as was the case with Tom Russell (LDA) and Jack Lemley (ODA).

lvi Yaneva and Heaphy 'Urban controversies'

lvii Yaneva and Heaphy, Ibid, p.33

lviii ODA Design Principles for the Olympic Park (London: ODA, 2007)

lix Kathleen Lloyd and Christopher Auld 'Leisure, public space and quality of life in the urban environment' Urban Policy and Research 21(4), 2003, pp.339-356

${ }^{1 x}$ Lloyd and Auld, Ibid, p.349

lxi Graeme Evans 'London 2012' In Olympic Cities: City Agendas, Planning and the World's Games 1896-2016 John Gold and Margaret Gold (Eds) (Abingdon: Routledge, 2010, pp.359-389)

lxii Greater London Authority 'The London Legacy Development Corporation. Report to Budget and Performance Committee', October 2013

lxiii Nesta 'Rethinking Parks: Exploring new business models for parks in the $21^{\text {st }}$ century', November 2013

lxiv The author acknowledges the funding and governance dilemmas here. There are problems caused by focusing on commercial income but there are also problems if this is avoided; not least the difficulties maintaining parks with insufficient resources. 